\section{Representaciones sociales de la recepción mediática durante la cuarentena por la COVID-19 en Colombia: entre mensajes y significados}

\author{
Social representations of media reception during \\ the COVID-19 lockdown in Colombia: from \\ messages to meanings
}

\section{Representações sociais da recepção midiática durante a quarentena pela COVID-19 na Colômbia: entre mensagens e significados}

Miguel Garcés-Prettel

Luis Ricardo Navarro-Díaz 2

Luis Guillermo Jaramillo-Echeverri 3

Yanin Santoya-Montes 1

\title{
Resumen
}

Las investigaciones recientes sobre la COVID-19 se han centrado en los efectos de esta pandemia en la salud pública, así como en los controles de bioseguridad y sus implicaciones socioeconómicas. El presente estudio mixto aporta una nueva mirada acerca del tema, combinando estrategias cualitativas y cuantitativas para identificar las representaciones sociales de la recepción mediática, en un sector de la población en Colombia, durante la cuarentena por la COVID-19. Los resultados indican que estas representaciones son diversas y están asociadas con el canal mediático y la afectación que produce la recepción en el estado de ánimo y la salud mental. En total, se realizaron 80 entrevistas y 1.068 encuestas online en diferentes regiones de Colombia. En la fase cualitativa se encontró que los programas o mensajes recibidos fueron representados positivamente, cuando provienen de la recepción de entretenimiento audiovisual y contribuye a la unidad familiar y a reducir el estrés en la cuarentena. De modo contrario, la recepción mediática fue representada negativamente, cuando los mensajes o noticias recibidas provienen del periodismo o las redes sociales y aumenta la desinformación, la angustia y el miedo al contagio. En la fase cuantitativa se encontró que la recepción mediática disminuyó a medida que trascurría la cuarentena, debido a la sobresaturación informativa y a la proliferación de noticias que enfatizan los riesgos de la COVID-19. Los resultados revelan la necesidad de enfocar la comunicación en salud al desarrollo de habilidades informacionales que permitan a la ciudadanía aprender a evaluar la veracidad y relevancia de la información recibida en la pandemia.

Percepción Social; Medios de Comunicación; Cuarentena; COVID-19

Correspondencia

M. Garcés-Prettel

Universidad Tecnológica de Bolívar.

Trasversal 48a n. 23 a 101, Cartagena / Bolivar - 130010,

Colombia.

mgarces@utb.edu.co

1 Universidad Tecnológica de Bolívar, Cartagena, Colombia.

2 Universidad Simón Bolivar, Barranquilla, Colombia.

3 Universidad del Cauca, Popayán, Colombia. 


\section{Introducción}

La pandemia por la COVID-19 representa un desafío mundial en materia de salud pública. Las naciones han tomado medidas para prevenir el aumento masivo de contagios y evitar un mayor número de muertes, así como el colapso del sistema de salud, sobre todo en los países latinoamericanos, donde las condiciones de inequidad y vulnerabilidad social agravan el impacto de la pandemia y condicionan la capacidad de respuesta de los sistemas públicos de salud. Por otra parte, el estado de emergencia sanitaria ha originado un aislamiento social en todos los grupos etarios, lo que significa que actividades cotidianas como el trabajo, el ocio y los tiempos en familia coexistan en un mismo sitio, difuminando los límites espacio-temporales entre los ámbitos tradicionalmente diferenciados de producción y reproducción social 1.

En este sentido, el alcance de la pandemia por la COVID-19 ha suscitado un interés, no solo de los gobiernos, la ciudadanía y las instituciones, como la Organización Mundial de la Salud (OMS), en intervenir y evaluar su impacto, sino también de académicos e investigadores que han realizado estudios epidemiológicos enfocados a la comorbilidad y la afectación en pacientes contagiados 2,3, el manejo médico ${ }^{4}$, la seguridad personal 5 , la evaluación de factores de riesgo en trabajadores de salud 6 y las implicaciones socioeconómicas producto de la pandemia 7; estudios que forman parte de características estructurales de las sociedades latinoamericanas, lo cual no afecta solamente al personal de la salud.

En Colombia el presidente y sus gobernantes locales adoptaron políticas y estrategias para el autocuidado frente a la COVID-19. En primer lugar, suspendieron temporalmente mediante decretos actividades educativas. En segundo lugar, restringieron la movilidad en las ciudades, aumentaron recursos en salud e incrementaron ayudas a la población más vulnerable. Una medida importante fue la implementación de una cuarentena (Decreto 457 del 22 de marzo de 2020) que inició el 24 de marzo y por razones preventivas se extendió hasta el 1o de septiembre de 2020; esto, con el fin de mitigar posibles contagios, promover preventivamente el distanciamiento social y fortalecer los centros de atención primaria.

Ahora bien, trabajos afines al tema indican que en contextos de pandemia resulta importante recibir, desde el campo de la salud, información completa y veraz ${ }^{8}$, así como difundir informes socialmente responsables; es decir, informar dónde acudir frente al contagio de casos sospechosos, qué criterios tener en cuenta y qué medidas preventivas asumir, lo que ayuda a reducir la incertidumbre y confusión de cómo actuar frente a la pandemia; así como preservar, de cierto modo, la salud física y mental de sus habitantes 9 .

Estudios recientes evidencian una relación entre el aumento de noticias producidas y mensajes emitidos por los gobiernos durante la pandemia, siendo los medios digitales los canales por donde más se informa a las personas sobre un posible contagio por la COVID-19 10. Igualmente, se sabe que el interés de estar informado sobre el tema, desde el campo periodístico, se traduce en una mayor receptividad informativa, sobresaliendo los noticieros como el medio más preferido de la población 11.

Desde estas lógicas de producción mediática, los análisis de Alfonso \& Fernández 12 apuntaron a la relación entre la sobresaturación de información (infodemia) y el aumento de la desinformación y creencias erradas sobre la COVID-19. Del mismo modo, el estudio de Andreu-Sánchez \& Martín-Pascual 13 reveló que imágenes falsas o ilustraciones imaginarias sobre la COVID-19 prevalecen en todas las fuentes de información, con excepción de las documentadas en enciclopedias o artículos científicos.

Otros investigadores encontraron que la televisión y las redes sociales aumentan la percepción de miedo, cuando se tiende a exagerar una situación crítica 14. Por ejemplo, Salaverría et al. 15 identificaron cuatro tipos de engaños o mensajes falsos percibidos como verdaderos, los cuales fueron manifestados en forma de broma, exageración, descontextualización y artificio, relacionados con la desinformación en las redes sociales en tiempos de pandemia. A su vez, Pedrozo-Pupo et al. 16 evidenciaron la prevalencia de variables asociadas con el estrés percibido en medio de la pandemia. En esta investigación, la prevalencia de estrés, además de ser alta, se relacionó con la percepción de inconsistencia entre acuerdos de las autoridades de salud y la recomendación de estudios científicos. Los autores sugieren la necesidad de más investigaciones sobre aspectos psicosociales producidos por la pandemia. 
La presente investigación se suma a la comprensión de impactos sociales producidos por la COVID-19, especialmente en contextos latinoamericanos, aportando una mirada desde los medios o comunicacional. Por tanto, se propone responder a dos preguntas: ¿Qué representaciones sociales poseen los colombianos frente a la recepción mediática en contextos de pandemia? y ¿qué tipo de programas televisivos, mensajes y noticias han recibido frecuentemente durante la cuarentena por la COVID-19?

La recepción mediática hace alusión a la exposición activa a los medios masivos; además, es un espacio productor de sentidos emergentes dentro de un contexto sociocultural e histórico 17. En el presente estudio, se analizó esta recepción a partir de la exposición a mensajes, noticias y programas provenientes de los medios de comunicación en el contexto de la pandemia. Analizar la recepción desde las representaciones sociales contribuyó a identificar procesos de producción de sentido a nivel comunicacional en tiempos de cuarentena. El diseño de la investigación es coherente con la perspectiva sociocultural de la recepción que reconoce diversidad de audiencias, contextos y sentidos que rodean estos procesos comunicativos.

En consecuencia, las preguntas antes formuladas se justifican ya que, en crisis sanitarias de orden mundial, los medios cumplen una función significativa de informar sobre temas relevantes a la sociedad 14, especialmente, aquellos que guardan relación con el tema de la salud pública. No obstante, es importante reconocer que la pandemia es un problema complejo y, si bien la información en salud no genera una transformación automática de comportamiento de las poblaciones frente a las enfermedades 18 , es necesario que la ciudadanía reciba de los medios información útil y veraz sobre lo que está aconteciendo.

\section{Método}

Durkheim 19 fue uno de los primeros científicos sociales en identificar las representaciones sociales como producciones mentales colectivas. Sin embargo, fue Moscovici 20 quien fundamentó teóricamente este concepto, al definirlo como un corpus organizado de conocimientos y actividades psíquicas que inciden en la elaboración de comportamientos y procesos comunicativos que están arraigados a un sistema de valores, nociones y prácticas, que permiten a las personas orientarse en un contexto social para actuar sobre él.

Siendo así, las representaciones sociales entrañan procesos de consenso y disenso en la producción de significados. Constituyen una formación subjetiva y polimorfa, donde la cultura, la ideología y la pertenencia socio-estructural dejan su impronta, al tiempo que procesos afectivos, cognitivos, simbólicos y valorativos participan en su constitución ${ }^{21}$. Además, son el resultado de procesos comunicativos que permiten desarrollar formas de comprensión y producción de sentido de lo que sucede alrededor de las personas; incluso, de aquello que aparentemente no tiene sentido 22.

Ahora bien, metodológicamente Jodelet 23 propone tres esferas para comprender los procesos comunicativos respecto a cómo emergen las representaciones sociales. La primera es subjetiva, allí los sujetos crean representaciones a partir de sus experiencias, significados y vivencias individuales. La segunda es intersubjetiva, encuentro relacional donde las representaciones son creadas a partir de significados compartidos. La tercera es trans-subjetiva, involucra el aparato cultural, su estructura y las posiciones de poder simbólico de las personas.

Evidentemente, representaciones y procesos comunicativos son inseparables, en tanto la comunicación no es solo transmisión de mensajes, sino intercambio activo de significados entre las personas 24; es decir, las representaciones sociales involucran significados relacionales y simbólicos, en el sentido que tienen que ver con percepciones, mediaciones, vínculos e interacciones emergentes. Es desde este contexto comunicacional donde se fundamentó el presente estudio, que tiene por objetivo identificar las representaciones de la recepción mediática en contextos de pandemia por la COVID-19, así como los tipos de programas, mensajes y noticias recibidas por los colombianos durante la cuarentena.

En relación al diseño se utilizó un método mixto, en tanto se combinaron estrategias comprensivas y explicativas a partir de dos fases: una cualitativa que intentó comprender las representaciones 
sociales sobre la recepción mediática; y una cuantitativa que tuvo como fin caracterizar los programas e información recibida durante la cuarentena.

La fase cualitativa fue mediante muestreo teórico. La selección de los participantes se desarrolló de manera intencional y voluntaria; además, que cumplieran con los siguientes requisitos: colombianos que estuvieran pasando la cuarentena en su país y que pertenecieran al área urbana o rural de su región. Siendo así, los participantes provinieron de 14 ciudades capitales: Cartagena, Barranquilla, Bogotá, Medellín, Valledupar, Meta, Santa Marta, Maicao, Pasto, Tunja, Montería, Riohacha, Arauca y Bucaramanga; y 18 municipios rurales: Piedecuesta, Funza, Turbaco, Bello, Alvarado, Acacias, Mahates, San Juan, Turbo, La Mesa, El Carmen, Soplaviento, Montecristo, Magangue, San Jacinto, Fundación, Moñitos y Talameque. En la selección se atendieron los lineamientos éticos, según los principios de la Declaración de Helsinki, sobre investigaciones con seres humanos; por tanto, participantes menores de 14 años no se tuvieron en cuenta, pues los padres de familia, en la mayoría de los casos, fueron reacios a firmar el consentimiento informado.

Seguidamente, se realizaron 80 entrevistas a hombres y mujeres. Estas se efectuaron con previo consentimiento informado mediante preguntas abiertas que indagaron sobre cómo percibían los participantes la cuarentena y cómo la relacionaban con la información recibida por parte de los medios. Ahora bien, en esta fase se esperaba una participación de 100 personas; no obstante, solo 80 aceptaron la invitación y respondieron la entrevista. Todas las entrevistas se transcribieron y codificaron con la ayuda del software AtlasTi 8 (http://atlasti.com/), lo que permitió identificar categorías emergentes gracias al Método de Comparación Constante propuesto por la Teoría Fundamentada 25,26.

Por otra parte, en la fase cuantitativa se aplicaron encuestas online para identificar los mensajes, programas televisivos y noticias recibidas durante la cuarentena. La participación fue voluntaria; al igual que en la fase cualitativa, el criterio de selección fue ser colombiano que se encontraba en su país pasando la cuarentena. La recolección de los datos se realizó con apoyo de 165 universitarios que fueron capacitados virtualmente en el acceso y diligenciamiento del instrumento. Este grupo se encargó de enviar los cuestionarios mediante correo electrónico y redes sociales a personas que forman parte de sus círculos familiares, tanto en el ámbito local, como nacional.

La encuesta constó de dos escalas confiables: la Escala de Medios e Información (EMI) y la Escala de Noticias sobre la COVID-19 (ENC). Ambas fueron diseñadas por el equipo investigativo. Se diligenciaron 1.068 encuestas online con consentimiento informado por parte de los participantes, de estos un $36,1 \%$ son hombres y un 63,9\% mujeres. Las edades comprendidas fueron: de 15 a 18 años (14,4\%), de 19 a 26 años (36,4\%), de 27 a 39 años (15,9\%), de 40 a 59 años $(28,9 \%)$ y de 60 a $91(4,5 \%)$.

De acuerdo con el tamaño de la población colombiana, y basados en un error del 2,5\%, una desviación de 1,96 y una varianza muestral de 0,25, se esperaba una participación de 1.537 participantes; sin embargo, solo respondieron a la invitación 1.068. Por otra parte, la prueba piloto realizada con 120 personas de diferentes edades permitió evaluar la comprensión del contenido de la encuesta e identificar un promedio de respuesta general de 15 minutos por participante.

La EMI dispuso de 9 ítems que evaluaron en un rango de 1 (nunca) a 4 (muy frecuentemente) la recepción mediática de programas o mensajes más vistos o recibidos durante la cuarentena, por ejemplo: series o películas, realitys, programas culturales, programas de humor, información en redes sociales, memes o caricaturas, información religiosa, noticias diarias y programas con información médica. Estos ítems explican en un 59,9\% la varianza total de la recepción mediática $(\mathrm{KMO}=0,77$; $\left.\chi^{2}=2331 ; p=0,00\right)$. La consistencia interna de esta escala fue 0,71.

La ENC estuvo compuesta por 8 ítems que evaluaron en un rango de 1 (nunca) a 4 (muy frecuentemente) la recepción mediática relacionada con noticias sobre la COVID-19. Los encuestados respondieron preguntas sobre noticias recibidas acerca del virus: contagiados, muertos por la COVID-19, recuperados, personas no infectadas, proezas y recomendaciones médicas. Estos ítems explicaron en un $67,7 \%$ la varianza total de la recepción de noticias $\left(\mathrm{KMO}=0,83 ; \chi^{2}=3817 ; \mathrm{p}=0,00\right)$. La consistencia interna de esta escala fue de 0,83 . Estos valores indican que, pese a que la recolección de datos se hizo en un contexto mediado por el uso de tecnologías digitales y por las condiciones de la pandemia que requieren mantener distanciamiento social, tanto las escalas, como los datos obtenidos por medio de estas, arrojaron buenos niveles de fiabilidad estadística.

La información se procesó con el software SPSS 26 (https://www.ibm.com/). Los datos de cada encuesta se actualizaban una vez el participante respondía por completo el instrumento; por tanto, 
no se guardaron encuestas sin finalizar. Los estudiantes que apoyaron el proceso supervisaron que la encuesta llegará a su destino, a fin de repetir el envío si era necesario. No se recopiló información personal que permitiera la identificación de los participantes, a fin de mantener los lineamientos éticos que proporciona el anonimato en el interior de un entorno online con fines investigativos 27. Solamente el investigador principal y la coordinadora encargada tenían acceso a la base de datos, tanto de la entrevista, como de la encuesta con su respectiva contraseña.

\section{Resultados}

Como se describió en el método, los hallazgos comprendieron dos fases, una cualitativa y otra cuantitativa. Para mayor comprensión de los resultados, ambas fases se presentarán por separado; no obstante, en la discusión se interrelacionaron, a fin de responder al carácter mixto de esta investigación, y señalar similitudes o diferencias respecto a otros estudios.

\section{Fase cualitativa}

La comprensión lograda permitió identificar diversas maneras de cómo los colombianos representaron la recepción mediática durante la cuarentena. Las representaciones comprendieron tres ámbitos de acceso mediático: los medios audiovisuales, el periodismo y los medios digitales, que abarcan mensajes provenientes de redes sociales y la web. Esto permitió considerar el canal mediático (tipo de medio) como categoría de análisis en el estudio; sin embargo, en las representaciones identificadas emergieron subcategorías que pueden apreciarse en la Figura 1, diseñada a manera de red o estructura temática con el apoyo del software AtlasTi 8.

Según la estructura, se observa que en el ámbito audiovisual los participantes representaron la recepción mediática con ver frecuentemente series y películas durante la cuarentena. Esta recepción fue un factor que favoreció el entretenimiento y la integración familiar; según los participantes, esto contribuyó a la unidad familiar, el fortalecimiento de la comunicación, la distracción y la reducción del estrés producido por la cuarentena. Como ejemplo, esto se observó en los siguientes relatos:

"El hecho de reunirse en familia y pasar el tiempo conversando, compartiendo una película, reduce el estrés y nos distrae de las preocupaciones que nos causa el coronavirus" (Entrevistado \#1).

"Considero que hemos aprendido a estar más en familia, a estar unidos, viendo películas, series, compartiendo mensajes positivos e implementando juegos de mesa para generar distracción y olvidarnos de la situación que estamos viviendo" (Entrevistado \#2).

Los relatos permitieron comprender que la recepción audiovisual es valorada por los participantes de manera positiva, en la medida que fortalece vínculos familiares y abre espacios para el diálogo y el encuentro familiar, a través de la recepción colectiva de series o películas. Recepción que además se representa como un recurso que ayuda a paliar por momentos la tensión que rodea a las familias por causa de la pandemia.

Desde el ámbito periodístico los participantes relacionaron la información recibida con noticias negativas, lo que pudo afectar su estado de ánimo y salud mental, además de convertirse en un foco de ansiedad. Algunos testimonios relacionados con estas categorías fueron:

"Aunque las noticias sobre el Coronavirus son muy desalentadoras, en esta cuarentena he tratado de no estresarme demasiado" (Entrevistado \#3).

"Con tanto manejo de información errónea y verdadera, se llena uno de angustia, además de impotencia..." (Entrevistado \#4).

Las representaciones vinculadas con noticias negativas hizo que la información periodística fuera comprendida de dos maneras: en primer lugar, como un factor generador de estrés y desánimo, lo que afectó, de cierta manera, la salud emocional de los participantes; en segundo lugar, como objeto de duda o sospecha, debido a la proliferación de información errónea, percepción que cuestiona la credibilidad de la información recibida, aumentando las preocupaciones e incertidumbres frente a la evolución de la pandemia. 
Figura 1

Representaciones de la recepción mediática en las semanas de cuarentena.

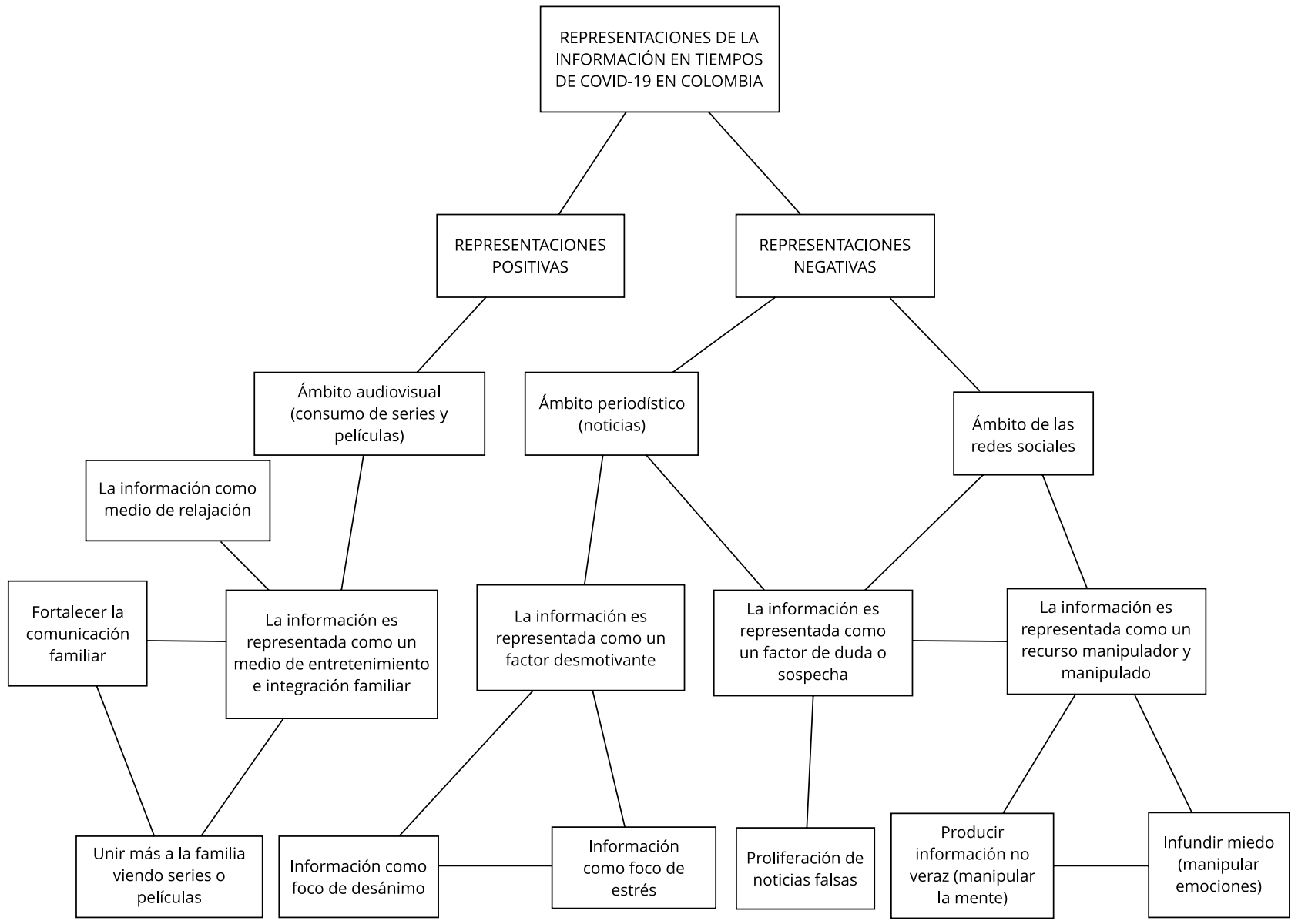

En el ámbito digital, la recepción mediática provino de redes sociales, la cual fue representada como estrategia de dominación, además de ser usada para manipular a la opinión pública. En los relatos se identifican críticas como:

"Trato de no pensar en la información que me mandan por WhatsApp, ya que la mayoría de las veces son cadenas para difundir miedo" (Entrevistado \#5).

"Estoy estresada por la cantidad de noticias que aparecen en las redes sociales y si uno no tiene en cuenta que tan veraz son, puede perjudicar nuestra salud mental" (Entrevistado \#6).

Los participantes asociaron la manipulación con la circulación de información o mensajes carentes de veracidad y con la afectación psicológica de experimentar miedos sociales que pueden ser nocivos para la salud.

En este sentido, las representaciones sociales asociadas a la pandemia implicaron una paradoja: mientras se dedicaron tiempos para estar en familia, en torno a medios audiovisuales de entretenimiento como series o películas, conversar y compartir, especie de olvido momentáneo de lo que se vivía fuera de sus casas, la recepción mediática proveniente de noticieros y redes sociales aumentó la zozobra y angustia al enterarse del aumento en los casos de personas contagiadas. Esto aumentó la incertidumbre al no sentirse seguros si la información recibida se sustentaba en la verdad o es parte de la tendencia mediática del momento. 


\section{Fase cuantitativa}

Las Figuras 2 y 3 evidencian la evolución semanal de la recepción mediática durante el periodo de cuarentena, evaluado entre el 24 de marzo y el 5 de junio de 2020 en Colombia.

Los datos de las Figuras 2 y 3 indican que la recepción de noticias y programas de entretenimiento, vinculada al ámbito audiovisual, fue frecuente o muy frecuente al comienzo de la cuarentena y se intensificó entre la tercera y sexta semana, cuando el gobierno extendió las restricciones de movilidad y los controles sanitarios para intentar aplanar la curva de contagio. No obstante, la recepción en el campo periodístico disminuyó progresivamente a partir de la séptima semana de cuarentena. Esta disminución es congruente con los resultados cualitativos obtenidos, que relacionan la actitud de los entrevistados de evitar o regular el acceso a mensajes alusivos a la pandemia, debido a la saturación y proliferación de contenidos noticiosos que aumentan la angustia, el miedo y el estrés.

Lo expuesto guarda relación con lo señalado por Alfonso \& Fernández 12, quienes consideran cómo la crisis de salud generada por la COVID-19 ha traído consigo una infodemia, caracterizada por la abundancia de información falsa y su rápida propagación entre las personas y medios, lo que coincide con lo expuesto por la OMS. En la Tabla 1 se evidencia el tipo de recepción mediática frecuente en el ámbito audiovisual y digital durante la cuarentena.

Los datos de la Tabla 1 evidencian que los mensajes más vistos por los colombianos entre los que se encuentran memes, caricaturas e información general (incluyendo noticias), provinieron entre un $78,7 \%$ y un $86,8 \%$ de las redes sociales y la web. Seguidamente, sobresale la recepción de series y películas (71\%), programas culturales y educativos (54,9\%) y otros de tipo médico o científico (52,5\%), provenientes de la televisión y canales streaming. Los realitys, programas de humor y religiosos fueron los menos vistos por los encuestados.

Por otra parte, la Tabla 2 evidencia en el ámbito periodístico la información noticiosa sobre la pandemia que recibieron con mayor frecuencia los colombianos durante el período de la cuarentena.

\section{Figura 2}

Recepción audiovisual de programas de entretenimiento en las semanas de cuarentena.

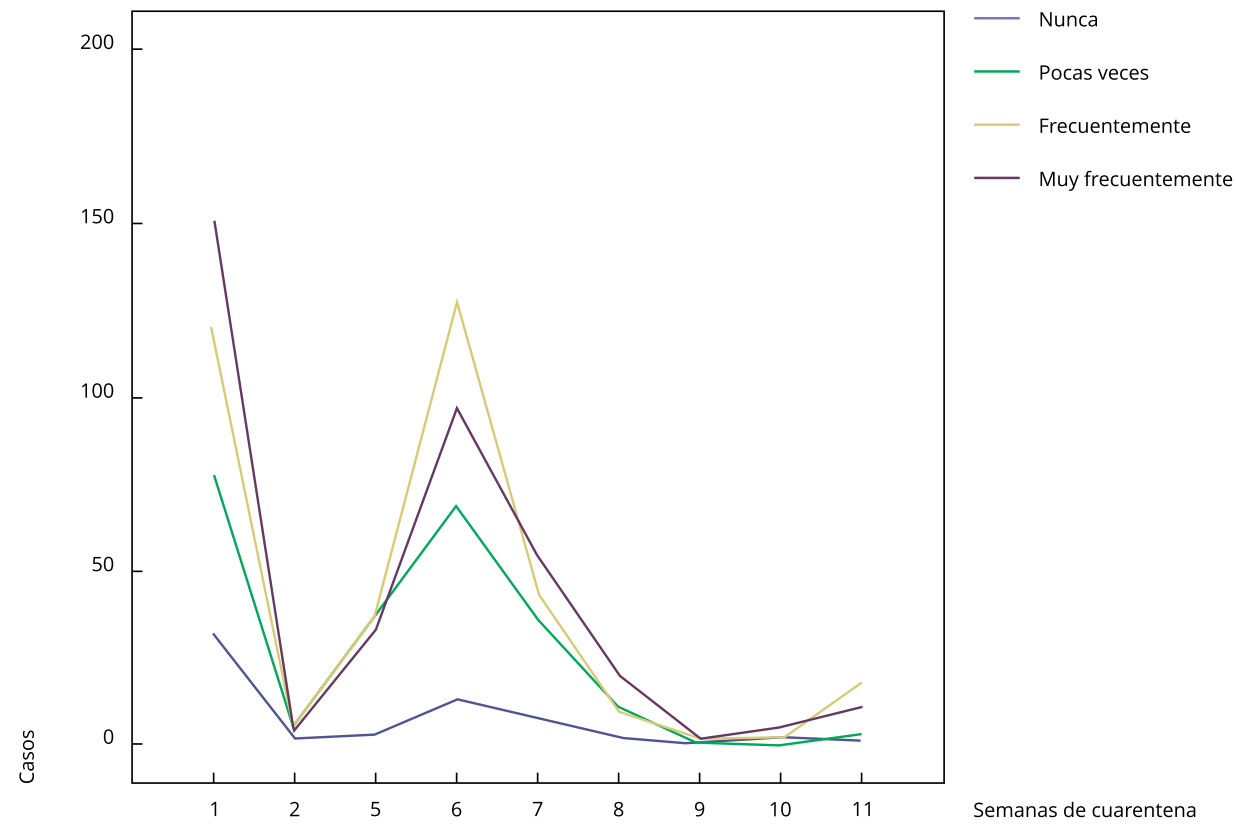


Figura 3

Recepción de noticias diarias en las semanas de cuarentena.

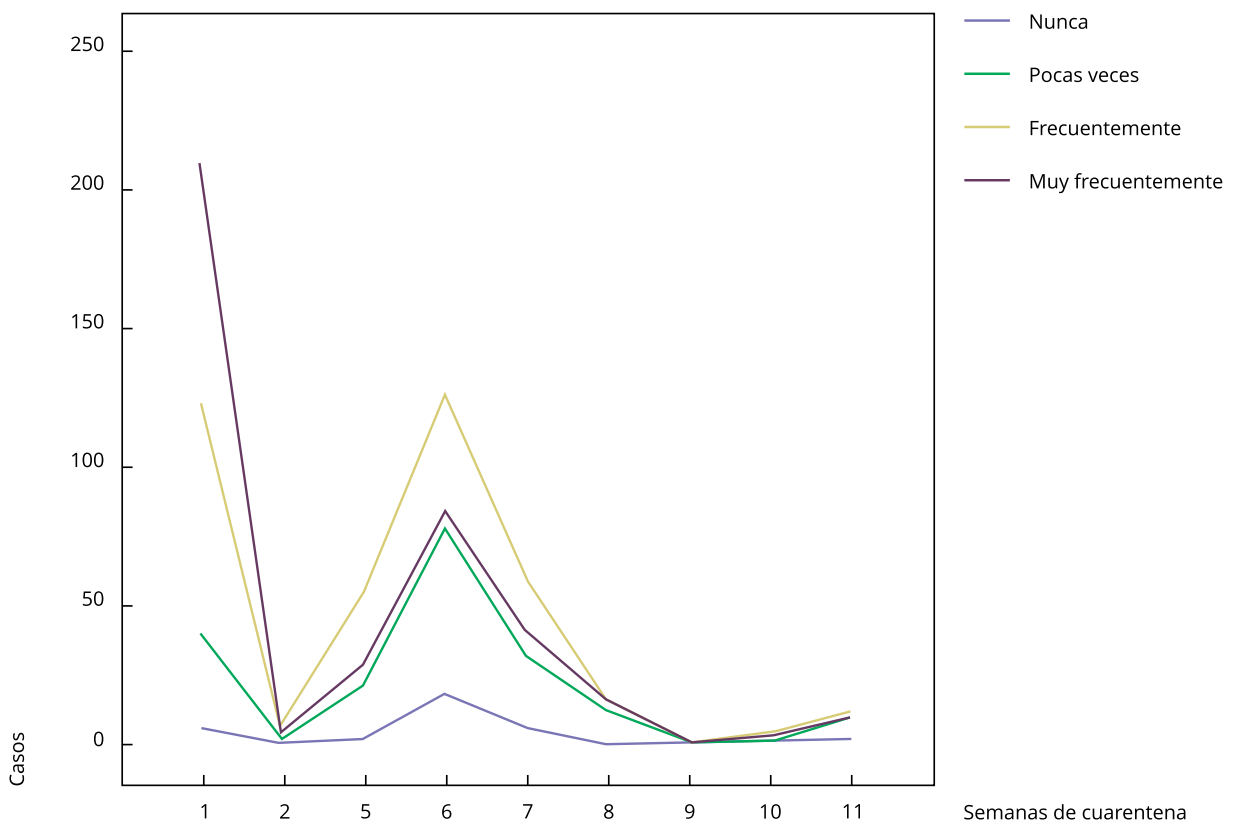

\section{Tabla 1}

Programas televisivos y mensajes recibidos durante las semanas de cuarentena.

\begin{tabular}{lc}
\hline Información audiovisual y digital & $\begin{array}{c}\text { Consumo frecuente y } \\
\text { muy frecuente (\%) }\end{array}$ \\
\hline Información general proveniente de las redes sociales & 86,8 \\
Memes o caricaturas que circulan en la web y las redes sociales & 78,7 \\
Series y películas & 71,0 \\
Programas culturales o educativos & 54,9 \\
Programas con contenido médico o científico & 52,5 \\
Programas de humor & 51,8 \\
Programas religiosos & 40,5 \\
Reality shows & 31,8 \\
\hline
\end{tabular}

Fuente: equipo de investigación. 
Tabla 2

Información periodística sobre la COVID-19 recibida durante las semanas de cuarentena.

\begin{tabular}{lc}
\hline Temas informativos sobre la pandemia & $\begin{array}{c}\text { Consumo frecuente y } \\
\text { muy frecuente (\%) }\end{array}$ \\
\hline Noticias sobre recomendaciones para prevenir el contagio & 89,3 \\
Noticias sobre incremento de contagios por la COVID-19 & 85,9 \\
Noticias sobre muertes por la COVID-19 & 85,9 \\
Noticias sobre número de personas no infectadas & 60,0 \\
Noticias sobre personas recuperadas de la COVID-19 & 59,9 \\
Noticias sobre logros o hazañas médicas frente a la COVID-19 & 43,2
\end{tabular}

Fuente: equipo de investigación.

Los datos indican que las noticias sobre recomendaciones para el autocuidado fue el tipo de información recibida con mayor frecuencia con un $89,3 \%$, lo que indica la preocupación por un conocimiento fiable acerca de los cuidados físicos que se deben tener durante la pandemia. Sigue en su orden la recepción de noticias relacionadas con el incremento de casos de personas contagiadas y fallecidas por la COVID-19 con un $85,9 \%$.

En menor proporción se ubicó la recepción de noticias sobre personas no infectadas y recuperadas y sobre las hazañas médicas para contrarrestar el virus; este osciló entre un 43,2\% y un 60\%. El análisis de los datos indica a nivel general que la recepción mediática de tipo periodístico estuvo más enfocada en temas preventivos y en mensajes alarmantes encaminados a comunicar los riesgos del contagio.

\section{Discusión}

En el contexto de la salud pública disponer de información veraz y relevante sobre la pandemia por la COVID-19 es importante para que las personas conozcan las medidas preventivas, a fin de evitar el contagio y la propagación del virus. Por tal motivo, fue pertinente comprender las representaciones sociales de la recepción mediática en Colombia durante la cuarentena y el tipo de programas, información y mensajes recibidos en este período. Se sabe al respecto que la información en salud con soporte científico puede contribuir al empoderamiento de la recepción de esta información y a la capacitación de las personas para tomar decisiones respecto a su salud 28.

Los resultados obtenidos en las dos estrategias o fases metodológicas evidenciaron diversos modos de representar la recepción mediática en la cuarentena, los cuales están asociados con el ámbito de procedencia de las noticias, programas y mensajes recibidos, así como el impacto de la recepción en el estado de ánimo de las personas. Los participantes representaron positivamente mensajes o programas cuando la recepción provino del medio audiovisual. Esto se debió a que relacionaron este ámbito con ver series o películas que favorecen el entretenimiento, la relajación y la unidad familiar.

Asimismo, la representación fue valorada positivamente por los participantes, cuando la recepción audiovisual en familia fue percibida como coadyuvante en la reducción del estrés, el desánimo y angustias experimentadas durante la cuarentena; sin embargo, fue una reducción pasajera, en el entendido que no necesariamente el entretenimiento genera una conciencia social en tiempos de pandemia. Ahora bien, las representaciones valoradas positivamente contrastan con las valoraciones negativas atribuidas a la información procedente de noticieros y redes sociales que fueron asociadas como aumento de desánimo, estrés, incertidumbre y desconfianza.

Los resultados anteriores confluyen con otros estudios que señalan que las representaciones sociales son mediacionales y pueden surgir de intercambios colectivos 23 , como en el caso del ámbito audiovisual, cuyas representaciones fueron producto de la interacción familiar, los vínculos afectivos y el bienestar percibido a partir de la recepción televisiva, aspectos que posibilitan otras miradas sobre el papel integrador que pueden desempeñar estos medios durante la pandemia, en especial cuando la 
recepción mediática ayuda a fortalecer los vínculos entre las personas y reducir el estrés; sobre todo, en el interior de una cuarentena que trae consigo tensiones de convivencia familiar.

Por tanto, la recepción de programas de entretenimiento audiovisual puede en determinados momentos servir como mecanismo de afrontamiento colectivo para manejar el estrés y olvidar por momentos la situación de la pandemia. Sin embargo, estudios realizados en América Latina revelan, como el caso del Perú, una valoración negativa de los contenidos audiovisuales emitidos por televisión, los cuales están asociados con exageraciones y miedos sentidos durante la pandemia 14. En tal sentido, es necesario que los medios de comunicación evalúen la pertinencia de sus contenidos y se inclinen a producir entretenimiento de calidad para disfrutar de un ocio audiovisual y una conciencia que brinde oportunidades para propiciar una educación en salud 29.

Desde el ámbito digital, emergieron representaciones que las personas valoraron como negativas respecto a los mensajes recibidos desde la web y las redes sociales. Estos mensajes fueron asociados con manipulación de la opinión pública y desinformación para generar miedos o pánicos sociales que afectan la salud mental de los colombianos. De hecho, la mayoría de los participantes manifestaron recibir frecuentemente este tipo de mensajes. Este hallazgo converge con otros estudios que indican que los medios digitales son los canales más usados para estar informados durante la cuarentena sobre la COVID-19 10. Asimismo, existe evidencia empírica que revela cómo en las redes sociales se manipula con frecuencia la información 15 y se transmiten noticias falsas presentadas como verdad, las cuales se vuelven virales y forman parte de una creencia social que carece de evidencia científica 30.

La desinformación y manipulación en las redes sociales y la web fue percibida como un problema que resta credibilidad a la fuente y canal de información. Al respecto la literatura señala que el aumento en las creencias erradas sobre la COVID-19, como bañarse con agua caliente previene la infección o que el virus no se transmite en climas cálidos, está relacionado con la desinformación en redes sociales. Esto evidencia la necesidad de informar y educar en salud para fomentar la autonomía, la capacidad crítica y la toma de decisión, frente a la información que se recibe por estos medios, a fin de desenvolverse mejor en la compleja realidad de la pandemia 12.

Además, la proliferación de desinformación sobre la COVID-19, la angustia experimentada y la saturación de información 12 , aspectos que permitieron comprender por qué la recepción mediática fue altamente frecuente entre la primera y quinta semana de la cuarentena, y empezó a disminuir progresivamente a partir de la séptima semana. Algunos estudios denominan este fenómeno como "infodemia" o "neblina informativa", que hace que las personas opten por disminuir la recepción para evitar el aturdimiento ${ }^{8} \mathrm{y}$ el estrés 11.

Aun así, se requiere de estudios en Colombia que profundicen en la relación entre miedo, angustia, recepción mediática y estrés percibido. A su vez, se requiere de trabajos que analicen si estas variables presentan diferencias sociodemográficas, pues en el caso de los miedos vinculados a la COVID-19, se ha encontrado evidencia en otros países de que con la edad se aumenta la percepción de miedo, mientras que el nivel educativo está asociado con menores temores y percepciones de fatalismo frente a la pandemia 14. El uso exagerado de información y la descontextualización forman parte de los engaños o estrategias empleadas para desinformar en tiempos de pandemia 15.

En el ámbito periodístico la recepción mediática fue representada de manera negativa, hallazgo que emergió en la fase cualitativa, donde las noticias recibidas eran vistas como un factor que afecta el estado la salud mental de los colombianos, lo que guarda relación con la fase cuantitativa, donde una alta frecuencia de noticias recibidas durante la cuarentena fue percibida como desalentadoras. Si bien la recepción de noticias sobre recomendaciones para el autocuidado fue frecuente durante la cuarentena, para los participantes la mayor parte de la información periodística estuvo centrada en noticias sobre el incremento de muertes y contagios por la COVID-19.

Siendo así, los periodistas tienen el deber ético y social de proveer información completa y veraz; más aún si se tiene en cuenta que la evidencia empírica indica que la difusión de información socialmente responsable ayuda a reducir la incertidumbre, y a preservar la salud física y mental de las personas durante la pandemia 9 . Además, es importante que los periodistas también informen con veracidad sobre el número de personas no infectadas, personas recuperadas y logros médicos en la recuperación de los pacientes, asuntos noticiosos recibidos con menor frecuencia a los participantes.

Brindar un ángulo informativo completo contribuye a que las personas posean una salud mental más equilibrada, estén mejor informadas y menos estresadas durante la pandemia. Por ello, es 
importante visibilizar más el trabajo del personal de la salud, lo que puede ayudar a evitar agresiones físicas y amenazas contra estos por parte de personas que poco conocen del tema. En este sentido, los periodistas requieren de mayor formación y capacitación en salud sobre cómo ejercer su labor de manera profesional y educativa en estos tiempos de pandemia. A esto se suma que la recepción mediática, basada en contenidos médicos o científicos, fue menor, si se compara con la recepción de memes, caricaturas y mensajes provenientes de las redes sociales, asunto a tener en cuenta por parte de los medios de comunicación y los gobiernos estatales.

Por otra parte, es importante considerar a futuro las representaciones sociales de los periodistas sobre la pandemia, por cuanto estos influyen en las actitudes y comportamientos de las personas, así como en las prácticas de comunicación en salud pública 31. De ahí que, para informar con responsabilidad social, los periodistas deban conocer, corroborar e interpretar adecuadamente los datos procedentes de gobiernos y organizaciones en materia de salud pública. Además, requieren familiarizarse con una terminología epidemiológica básica para entender la pandemia. Desde esta perspectiva, la OMS 32 viene adelantando orientaciones a los periodistas sobre cómo evitar el pánico, sin generar una falsa seguridad o transparencia, a la hora de informar sobre las medidas de precaución que se deben tener en cuenta durante la pandemia. La transparencia es considerada una práctica esencial de comunicación de riesgos para informar y generar confianza con el público 33.

\section{Conclusión}

Las representaciones sociales de la recepción mediática en el contexto de la cuarentena por la COVID-19 emergieron de los procesos comunicativos puestos en escena por los participantes, a través de sus interacciones, vivencias y significados 23, a partir de la recepción de información proveniente de los medios. En general, se logró comprender que estas representaciones son diversas y valoradas por los participantes tanto positiva como negativamente, dependiendo de la información recibida, el canal mediático y la manera como la recepción puede afectar el bienestar familiar, psicológico y el estado de ánimo de las personas durante la cuarentena.

Por otro lado, y teniendo en cuenta la desinformación sobre la COVID-19 percibida en el ámbito digital, las estrategias de comunicación en salud deberían enfocarse en aportar al desarrollo de habilidades informacionales que permitan a los ciudadanos saber cómo encontrar, corroborar, y analizar la información que se recibe, con el fin de aprender a comprobar su veracidad y relevancia. Estudiar el papel que juega la información en relación con la salud pública en ambientes de pandemia es sumamente importante. Los medios de comunicación, aliados al sector de la salud, pueden ofrecer condiciones humanitarias en tiempos de pandemia; además, su labor social puede ayudar a tomar conciencia de los riesgos y cuidados que se deben adoptar antes, durante y después de una cuarentena. 


\section{Colaboradores}

M. Garcés-Prettel participó en la concepción, diseño del estudio, recolección de la información, análisis cuantitativo, discusión y elaboración del manuscrito. L. R. Navarro-Díaz participó en la construcción del marco teórico, antecedentes investigativos y el análisis de la información. L. G. Jaramillo-Echeverri participó en el diseño metodológico, el análisis cualitativo, y la discusión del manuscrito. Y. SantoyaMontes coordinó la recolección de la información y el análisis cuantitativo de la información. Todos los autores aprobaron la versión final del manuscrito.

\section{Informaciones adicionales}

ORCID: Miguel Garcés-Prettel (0000-0001-63913147); Luis Ricardo Navarro-Díaz (0000-00019397-8494); Luis Guillermo Jaramillo-Echeverri (0000-0002-8433-4002); Yanin Santoya-Montes (0000-0002-6098-2398).

\section{Agradecimientos}

Los autores agradecen al Programa de Comunicación Social de la Universidad Tecnológica de Bolívar, a la Universidad del Cauca y a la Universidad Simón Bolívar por facilitar los recursos académicos, tecnológicos y operativos para el desarrollo de la investigación.

\section{Referencias}

1. Moratalla AZ, Agea AA. Ciudad COVID 19: una nueva inequidad en el espacio y el tiempo urbano. Urbano 2020; 23:4-9.

2. Guan WJ, Liang WH, Zhao Y, Liang HR, Chen ZS, Li YM, et al. Comorbidity and its impact on 1590 patients with COVID-19 in China: a nationwide analysis. Eur Respir J 2020; 55:2000547.

3. Zhou F, Yu T, Du R, Fan G, Liu Y, Liu Z, et al. Clinical course and risk factors for mortality of adult inpatients with COVID-19 in Wuhan, China: a retrospective cohort study. Lancet 2020; 395:1054-62.

4. Balibrea JM, Badia JM, Pérez IR, Antona EM, Peña EA, Botella SG, et al. Manejo quirúrgico de pacientes con infección por COVID-19. Recomendaciones de la Asociación Española de Cirujanos. Cir Esp 2020; 98:251-9.

5. Cheung JC, Ho LT, Cheng JV, Cham EY, Lam KN. Staff safety during emergency airway management for COVID-19 in Hong Kong. Lancet Respir Med 2020; 8:e19.

6. Organización Mundial de la Salud. Evaluación de los factores de riesgo para la enfermedad por coronavirus (COVID-19) en trabajadores de la salud: protocolo para un estudio de casos y controles. Geneva: Organización Mundial de la Salud; 2020.

7. Bárcena A. Coyuntura, escenarios y proyecciones hacia 2030 ante la presente crisis de COVID-19. Santiago: Comisión Económica para América Latina y el Caribe; 2020.

8. Bórquez B, Luengo-Charath MX, Anguita V, Bascuñán ML, Pacheco IM, Michaud $\mathrm{P}$, et al. Uso y difusión responsable de la información en pandemia: un imperativo ético. Rev Chil Pediatr 2020; 91:794-9.

9. Segura MS. Con alerta, pero sin pánico. El rol de los medios durante la pandemia. Rev Fac Cienc Méd (Córdoba) 2020; 77:55-8.

10. Lázaro-Rodríguez P, Herrera-Viedma E. Noticias sobre COVID-19 y 2019-nCoV en medios de comunicación de España: el papel de los medios digitales en tiempos de confinamiento. Profesional de la Información 2020; 29(3). https://revista.profesionaldelainformacion. com/index.php/EPI/article/view/epi.2020. may.02.

11. Masip P, Aran-Ramspott S, Ruiz-Caballero C, Suau J, Almenar E, Puertas-Graell D. Consumo informativo y cobertura mediática durante el confinamiento por el COVID-19: sobreinformación, sesgo ideológico y sensacionalismo. Profesional de la Información 2020; 29(3). https://revista.profesionaldelainformacion. com/index.php/EPI/article/view/epi.2020. may. 12 .

12. Alfonso IR, Fernández M. Comportamiento informacional, infodemia y desinformación durante la pandemia de COVID-19. Anales de la Academia de Ciencias de Cuba 2020; 10:209-15. 
13. Andreu-Sánchez C, Martín-Pascual MA. Imágenes falsas del coronavirus SARS-CoV-2 en la comunicación de la información al comienzo de la pandemia del COVID-19. Profesional de la Información 2020; 29(3). https://revista. profesionaldelainformacion.com/index.php/ EPI/article/view/79361.

14. Mejía CR, Rodríguez-Alarcón JF, Garay-Ríos L, Enríquez-Anco M, Moreno A, Huancahuari-Ñanacc N, et al. Percepción de miedo o exageración que transmiten los medios de comunicación en la población peruana durante la pandemia de la COVID-19. Rev Cuba Invest Bioméd 2020; 39:e698.

15. Salaverría R, Buslón N, López-Pan F, León B, López-Goñi I, Erviti MC. Desinformación en tiempos de pandemia: tipología de los bulos sobre la COVID-19. Profesional de la Información 2020; 29(3). https://revista.profesional delainformacion.com/index.php/EPI/article/ view/epi.2020.may.15.

16. Pedrozo-Pupo JC, Pedrozo-Cortés MJ, Campo-Arias A. Perceived stress associated with COVID-19 epidemic in Colombia: an online survey. Cad Saúde Pública 2020; 36:e00090520.

17. Cantú A, Cimadevilla G. Orientación, consumo, recepción y uso de los medios: una propuesta de articulación conceptual. Intercom (São Paulo) 1998; 21:41-54.

18. Uchôa E, Vidal JM. Antropología médica: elementos conceituais e metodológicos para uma abordagem da saúde e da doença. Cad Saúde Pública 1994; 10:497-504.

19. Durkheim E. Representations individuelles et representations collectives. Paris: Université du Québec; 1898.

20. Moscovici S. Notes towards a description of social representations. Eur J Soc Psychol 1998; 18:211-50

21. Perera M. A propósito de las representaciones sociales: apuntes teóricos, trayectoria y actualidad. La Habana: Centro de Investigaciones Psicológicas y Sociológicas; 2003.

22. García Y. Representaciones sociales: aspectos básicos e implicaciones en la psicología. Rev Psicogente 2003; 11:4-16.
23. Jodelet D. Imbricaciones entre representaciones sociales e intervención. Guadalajara: Universidad de Guadalajara; 2007.

24. Rubira R, Puebla B. Representaciones sociales y mediaciones: una lectura crítica desde la perspectiva latinoamericana de comunicación. Barataria Revista Castellano-Manchega de Ciencias Sociales 2017; (22):81-97.

25. Strauss A, Corbin J. Bases de la investigación cualitativa: técnicas para desarrollar la teoría fundamentada. Medellín: Universidad de Antioquia; 2002.

26. Garcés-Prettel ME, Jaramillo-Echeverri LG. Avenida Ronda del Sinú: entre espacios y significados. Rev Luna Azul 2017; (44):247-64.

27. Markham AN. Los métodos, políticas y lineamientos éticos de representación en la etnografía online. In: Denzin NK, Lincoln Y, coordinadores. Manual de investigación cualitativa. v. 4 - Métodos de recolección y análisis de datos. Barcelona: Gedisa; 2015. p. 316-68.

28. Navas-Martin MA, Albornos-Muñoz L, Escandell-García C. Acceso a fuentes de información sobre salud en España: cómo combatir la infoxicación. Enferm Clín 2012; 22:154-8.

29. Ortiz Sobrino MA, Marfil Carmona R, Osuna Acedo S. Entretenimiento de calidad en el ocio audiovisual y digital: oportunidades para la educación en los medios y las industrias creativas del siglo XXI. In: Marta-Lazo C, editor. Calidad informativa en la era de la digitalización: fundamentos profesionales vs. infopolución. Madrid: Dykinson; 2018. p. 187-208.

30. Ferraris M. Posverdad y otros enigmas. Madrid: Alianza Editorial; 2019.

31. Sweet MA, Holland KE, Blood RW. Learning from journalists' experiences of the H1N1 pandemic. Med J Aust 2012; 197:544-5.

32. World Health Organization. Effective media communication during public health emergencies: a WHO handbook. Geneva: World Health Organization; 2005. (WHO/CDS/2005.31).

33. Fu KW, Zhu Y. Did the world overlook the media's early warning of COVID-19? J Risk Res 2020; 23:1047-51. 


\section{Abstract}

Recent studies on COVID-19 have focused on the pandemic's effects on public health and the biosafety controls and their socioeconomic implications. The current mixed-methods study takes a new look at the topic, combining qualitative and quantitative strategies to identify the social representations of media reception in a sector of the Colombian population during social isolation in the COVID-19 pandemic. The results indicate that these representations vary and are associated with the media channel and the effect the reception produces on mood and mental health. A total of 80 interviews and 1,068 online survey forms were applied in different regions of Colombia. The qualitative phase showed that the programs or messages received were represented positively when they came from audiovisual entertainment and contributed to the family unit and reduced stress during the lockdown. Meanwhile, media reception was represented negatively when the messages or news came from journalism or social networks and increased the misinformation, anxiety, and fear of contagion. The quantitative phase found that media reception decreased as the lockdown continued, due to information saturation and the proliferation of news emphasizing the risks of COVID-19. The results reveal the need to focus health communication on the development of information skills that allow people to learn and assess the veracity and relevance of information received during the pandemic.

Social Perception; Communications Media; Quarantine; COVID-19

\section{Resumo}

As pesquisas recentes sobre a COVID-19 têm focado os efeitos da pandemia sobre a saúde pública, bem como nos controles de biossegurança e suas consequências socioeconómicas. O presente estudo misto traz um novo olhar sobre a questão, combinando estratégias qualitativas e quantitativas para identificar as representações sociais da recepção midiática em um setor da população na Colômbia, durante a quarentena causada pela COVID-19. Os resultados apontam que estas representações são diversas e estão associadas ao canal informativo e ao modo como afetam o estado de espírito e a saúde mental. No total, foram realizadas 80 entrevistas e aplicados 1.068 questionários online em diferentes regiões do país. Na fase qualitativa verificou-se que os programas ou mensagens recebidas foram representados positivamente, quando provenientes de entretenimento audiovisual, contribuindo para a união familial e para reduzir o estresse na quarentena. Já a recepção midiática teve representação negativa, quando as mensagens ou notícias recebidas procedem do jornalismo ou das redes sociais, aumentando a desinformação, a angústia e o medo do contágio. Na fase quantitativa verificou-se que a recepção midiática diminuiu à medida que transcorria a quarentena, por causa da saturação informativa e da proliferação de notícias enfatizando os riscos da COVID-19. Os resultados revelam a necessidade de direcionar a comunicação em saúde para o desenvolvimento de habilidades informacionais que permitam à população aprender a avaliar a veracidade e a relevância da informação recebida durante pandemia.

Percepção Social; Meios de Comunicação;

Quarentena; COVID-19

Recibido el 14/Jul/2020

Versión final presentada el 22/Oct/2020

Aprobado el 11/Nov/2020 